\title{
Minería Chilena: Captura, Transporte, y Almacenamiento de Dióxido de Carbono en Relaves mediante Líquidos lónicos y Carbonatación Mineral
}

\author{
José O. Valderrama ${ }^{(1,2)}$, Richard Campusano ${ }^{(3)}$ y Cesar Espindola ${ }^{(4)}$ \\ (1) Universidad de Antofagasta, Facultad de Ingeniería, Departamento de Ingeniería Química y Procesos de Minerales, \\ Av. Angamos 601, Antofagasta, Chile (e-mail: joseovalderrama@gmail.com) \\ (2) Centro de Información Tecnológica (CIT), Monseñor Subercaseaux 667, La Serena-Chile \\ (3) Universidad de La Serena, Facultad de Ciencias, Dpto. de Física y Astronomía, Casilla 554, La Serena-Chile \\ (e-mail: rcampusano27@gmail.com) \\ (4) Universidad de La Serena, Facultad de Ingeniería, Dpto. de Ing. Industrial, Casilla 554, La Serena-Chile \\ (e-mail: cespindola@userena.cl)
}

Recibido Abr. 20, 2019; Aceptado Jun. 25, 2019; Versión final Ago. 1, 2019, Publicado Oct. 2019

\begin{abstract}
Resumen
En este trabajo se reflexiona y analiza la situación de la minería chilena y su relación con temas medioambientales, y presenta una propuesta sobre la captura de dióxido de carbono $\left(\mathrm{CO}_{2}\right)$ y su secuestración en relaves mineros. Se discuten algunos aspectos sobre el cambio climático, sobre el efecto invernadero y sobre la huella del carbono. Se analiza cómo la industria minera, no solo en Chile sino en otras partes del mundo, puede hacer uso de uno de los recursos en creciente formación (como los relaves) para mitigar el problema de generación de dióxido de carbono de sus procesos, en especial, las plantas de potencia que proveen de energía a los procesos mineros y metalúrgicos. Se propone la secuestración de $\mathrm{CO}_{2}$ mediante carbonatación, como una forma adicional para reducir la cantidad de gases nocivos emitidos a la atmósfera. Se propone finalmente un método para la captura de $\mathrm{CO}_{2}$ de gases de chimenea y para su transporte al lugar de secuestración usando líquidos iónicos. Se concluye que a pesar que los costos de secuestración son aún altos, hay que trabajar en la optimización de los procesos para hacer económicamente viable esta alternativa de captura y almacenamiento de $\mathrm{CO}_{2}$ mediante líquidos iónicos en relaves mineros, en el menor tiempo posible.
\end{abstract}

Palabras clave: minería chilena; captura de $\mathrm{CO}_{2}$; relaves mineros; líquidos iónicos; carbonatación mineral

\section{Chilean Mining: Capture, Transport, and Storage of Carbon Dioxide in Tailings using lonic Liquids and Carbonation.}

\begin{abstract}
This work analyzes and discusses the current situation of Chilean mining and its relation with environmental issues and with a proposal for capturing, transporting and sequestering carbon dioxide $\left(\mathrm{CO}_{2}\right)$ in mine tailings. Some aspects related to climate change, greenhouse effect, and carbon footprint are discussed. Also, analysis is done on how the mining industry, not only in Chile but around the world, can make use of raw material being permanently formed such as the waste material forming mine tailings, to mitigate the problem of excess of $\mathrm{CO}_{2}$ in the atmosphere, mainly formed in power plants that provide energy to the mining and metallurgical processes. Also, sequestration of $\mathrm{CO}_{2}$ is analyzed as a viable alternative to reduce the amount of harmful gases in the atmosphere. Finally, a method for the capture of $\mathrm{CO}_{2}$ contained in flue gases and its transport to the place of sequestration using ionic liquids is proposed. It is concluded that despite the costs of sequestration are still high, work must be done to optimize processes for making the technology economically viable for the capture and transport of $\mathrm{CO}_{2}$ using ionic liquids and its sequestration in mineral tailings, in the shortest possible time.
\end{abstract}

Keywords: chilean mining; capture of de $\mathrm{CO}_{2}$; mine tailings; ionic liquids; mineral carbonation 


\section{INTRODUCCION}

Aunque con algún retraso, la comunidad internacional ha ido entendiendo y aceptando que las emisiones de dióxido de carbono $\left(\mathrm{CO}_{2}\right)$ y otros gases, definidos en el protocolo de Kioto el año 2005, constituyen uno de los problemas más importantes que enfrenta la humanidad hoy en día. A fines de 2018 se registraron los niveles más críticos de contaminación atmosférica debido a la presencia de esta sustancia y otras igualmente dañinas, registrándose una concentración media de $\mathrm{CO}_{2}$ de 405.5 partes por millón (ppm) lo que representa el $146 \%$ del nivel que había en la era pre industrial (antes de 1750). Así también, se registraron aumentos en las concentraciones de metano, óxido nitroso y la reaparición del triclorofluorometano (CFC-11), un potente gas que contribuye, junto a los otros, a desestabilizar el efecto invernadero (OMM, 2018). Se suma a este fenómeno la intensificación de los efectos del calentamiento global cada vez más evidentes en distintas latitudes del planeta donde están ocurriendo fenómenos no vistos antes en esos lugares (sequías, inundaciones, heladas, olas de calor, y desprendimiento de glaciares, entre otros). Ante este escenario la respuesta lógica es tratar de encontrar una solución a dicho problema, en especial desde la ciencia, cuando los avances en los acuerdos internacionales no han logrado conseguir un compromiso global que permita pensar en una solución real a esta problemática global. Lo anterior, se puede deber al gran crecimiento económico, urbanización, y cambio en la forma de vida de las personas, que lamentablemente han tenido un impacto negativo en varias partes del mundo, principalmente en el sector Asia-Pacífico, en el que 25 de las 30 ciudades más contaminadas del mundo se encuentra en dicho territorio (BCN, 2017).

Aunque el cambio climático siempre ha existido, la naturaleza ha logrado hacer los ajustes necesarios para su mitigación y para la adaptación de la vida a nuevos escenarios. Sin embargo, por la intervención humana el cambio está llegando a límites que la naturaleza no puede soportar. Es así que este fenómeno no es hoy en día solo un problema ambiental, sino que constituye un problema de desarrollo, con profundos impactos potenciales en la sociedad, la economía y los ecosistemas (Pandey et al., 2010). Solo por considerar uno entre muchos otros impactos del cambio climático, la absorción oceánica de las emisiones antropogénicas de dióxido de carbono está cambiando la química del agua de mar, en un proceso conocido como acidificación oceánica, lo que provoca cambios en el dominio de las macroalgas, la degradación del hábitat y la pérdida de biodiversidad (Hall-Spencer y Harvey, 2019), considerando que los océanos, regulan el clima, producen oxígeno, son el hábitat de una gran variedad de seres vivos, nos proporcionan medicinas, alimentos, trabajo y que además ocupan el $71 \%$ de la superficie del mundo, los riesgos para los bienes y servicios marinos se amplifican y proyectan graves consecuencias para millones de personas. Además, el acelerado proceso de acidificación de los océanos, producto de las emisiones excesivas del $\mathrm{CO}_{2}$ hacia la atmósfera, ha hecho que se ponga en riesgo el sano desarrollo de los arrecifes de coral, los mariscos y otras formas de vida presentes en los océanos (ECOticias, 2018). Por esto es que los gobiernos e instituciones internacionales han estado implementando una serie de acciones que ayudan a la mitigación de las emisiones de gases efecto invernadero (GEI) provenientes de la actividad humana y al desarrollo de métodos para cuantificar los efectos de dichos gases (WRI, 2004). Para ello, se han creado organizaciones a escala nacional e internacional para el estudio y reflexión sobre el tema y para la creación de herramientas de transferencia tecnológica y financiera que permitan paliar los drásticos y dañinos cambios que nosotros mismos ayudamos a generar. Está faltando, sin embargo, pasar lo más pronto posible de los debates, ideas, y opiniones a las acciones concretas en terreno.

Existen diversas estrategias para disminuir las emisiones de $\mathrm{CO}_{2}$ y con ello mitigar el cambio climático no habiendo ninguna que por sí sola permita solucionar el problema. Se trata entonces de una situación en que se deben involucrar todos los gobiernos con políticas globales de reducción del uso de combustibles fósiles, la promoción del uso de energía limpias, la prohibición de usos de materiales contaminantes (por ejemplo, los plásticos), y la exigencia de métodos seguros de tratamiento de desechos, entre otras medidas. Pero eso no bastará si no producimos un cambio drástico en nuestra manera de vivir. También se puede mencionar otras estrategias tales como la recuperación y ampliación de los sumideros biológicos mediante, por ejemplo, la reforestación o la fertilización del fitoplancton marino o la captura del $\mathrm{CO}_{2}$ generado, para después inyectarlo y almacenarlo en formaciones geológicas del subsuelo, en el océano o en carbonatos minerales, con el propósito de aislarlo de la atmósfera. Esta última estrategia de captura y secuestro recibe el nombre de Captura y Almacenamiento de Carbono (CAC).

En Chile esta estrategia CAC podría encontrar un interesante espacio de desarrollo, especialmente en la industria minera, a partir de la captura y almacenamiento de $\mathrm{CO}_{2}$ en los relaves que dejan los procesos mineros. Sin embargo, la capacidad técnica de remover $\mathrm{CO}_{2}$ de las fuentes puntuales de emisión parece haber dejado de ser un problema tecnológico y se ha transformado en un problema económico porque las posibles soluciones disponibles tienen costos muy altos. Por ello es que son muy pocas las manifestaciones en gran escala de estas tecnologías. De esta manera, si bien teóricamente se puede capturar y secuestrar el $\mathrm{CO}_{2}$, el enfoque actual de las investigaciones está en optimizar económicamente los procesos utilizados. Lo anterior, concuerda con lo planteado en una entrevista al presidente ejecutivo de la empresa Antofagasta Minerals, en el sentido que el interés de la empresa radica en energía renovables no convencionales, no en el invertir en campo energético tradicional: "Las energías limpias son las que nos interesan, porque son las 
que ayudan a reducir nuestra huella de carbono y a mejorar el cambio climático, pero también son las que marcan precios más competitivos hoy en día. No queremos ser inversionistas en el campo energético (actual)" (LT-Pulso, enero 2019).

En este trabajo se reflexiona y analiza la situación de la minería chilena y su relación con temas medioambientales, con el tratamiento de relaves mineros y con una propuesta sobre la captura de dióxido de carbono en las fuentes de producción (plantas de potencia), usando líquidos iónicos, sobre su transporte al lugar donde están situados los relaves, y a su secuestración en los relaves. En ocho secciones se incluyen temas como cambio climático y energía, la huella de carbono (HdC), la energía en el sector minero, los relaves y su regulación, y la distribución de relaves en Chile. Se analizan procesos de captura y almacenamiento de $\mathrm{CO}_{2}$, y secuestración de $\mathrm{CO}_{2}$ mediante carbonatación incluyendo una propuesta, para la captura y trasporte de $\mathrm{CO}_{2}$ usando líquidos iónicos

\section{CAMBIO CLIMÁTICO Y ENERGÍA}

Desde hace mucho tiempo, pero en especial en los últimos 60 o 70 años, nosotros, los seres humanos, hemos mejorado sustancialmente nuestro estilo de vida pensando siempre en nosotros y no en lo que nos rodea, el medio ambiente. Nos hemos dado cuenta tarde (o simplemente preferimos ignorar) que el efecto de nuestras actividades que supuestamente mejoraban nuestra vida era extremadamente nocivo para nuestro entorno y cada actividad nueva lo hacía peor. La forma en que decidimos atender la creciente demanda de recursos naturales (deforestando) y de más y más energía (consumiendo combustibles fósiles, carbón, petróleo y gas natural) han contribuido a la alteración del balance de carbono en nuestra atmósfera, intensificando el llamado efecto invernadero uno de los responsables del cambio climático. Adicionalmente hemos acabado con importantes ecosistemas, hemos hecho desaparecer especies, y hemos contaminado aire, mar y tierra con nuestras basuras.

Se debe aclarar, sin embargo, que el efecto invernadero, además de haber existido siempre, es útil y necesario para la vida en el planeta si se mantiene un equilibrio entre el carbono que hay en la tierra, en el agua y en el aire, equilibrio que nos hemos encargado de modificar más allá de lo que la naturaleza puede manejar, sin cobrarnos por el daño. El efecto invernadero es el que hace posible el desarrollo de la vida en nuestro planeta. De no existir el efecto invernadero, omitiendo las explicaciones físicas, la temperatura de la tierra sería menor a 15 grados bajo cero (Montecinos y Carvajal, 2018). Con el uso de los combustibles fósiles, algunas sustancias perjudiciales tales como $\mathrm{CO}, \mathrm{SO}_{2}, \mathrm{NO}_{2}, \mathrm{CO}_{2}$, entre otras, que son vertidas a la atmósfera, el balance de carbono está actualmente en desequilibrio. Hay que tener presente, que los combustibles fósiles que utilizamos, son productos de procesos naturales que tomaron entre 300 y 500 millones de años en formarse y nosotros los hemos destruido en unos pocos cientos de años (Montecinos y Carvajal, 2018). A pesar del escepticismo de un grupo minoritario de científicos y de algunos líderes políticos más interesados en los aspectos económicos del problema, existe hoy en día consenso sobre la influencia de las actividades humanas en el deterioro global del planeta.

El efecto invernadero se origina por un problema de flujo de energía. La energía que llega del sol está formada por ondas de frecuencias altas que traspasan la atmósfera, sin mucha resistencia. La energía remitida hacia el exterior, desde la Tierra está formada por ondas de frecuencias más bajas, y es absorbida por los gases de la atmósfera, los que se calientan y ascienden a las capas más externas de la atmósfera, produciendo que aumente la temperatura bajo la necesaria capa por la disminución de la radiación hacia el exterior de la atmósfera debido a la presencia exagerada y fuera del equilibrio de los GEl (Bolin et al., 1986). No todos los GEI tienen la misma capacidad de provocar calentamiento global, ya que su intensidad depende de su poder de radiación y del tiempo promedio que la molécula del gas permanece en la atmósfera. Si estos dos factores se consideran juntos, al promedio de calentamiento que pueden causar, se le conoce como Potencial de Calentamiento Global (PCG).

A pesar de lo dañino que es el uso de los combustibles fósiles, la generación eléctrica a partir de este tipo de fuentes ha ido en aumento en Chile. De acuerdo a información del Boletín Mercado Eléctrico Sector Generación de enero 2018 (BME, 2018), a diciembre de 2017, de los 23.729 MW producidos en Chile, un $53.8 \%$ era origen térmico, un $28.4 \%$ de origen hídrico, un $6.0 \%$ de origen eólico, un $9.6 \%$ de origen solar, un $2.0 \%$ de biomasa y cogeneración y un $0.2 \%$ de geotermia. Este panorama debe ser revertido en los próximos años para dejar de ser contribuyentes del cambio climático y de nuestra propia destrucción.

\section{LA HUELLA DE CARBONO}

En los últimos años se han desarrollado varias herramientas de cuantificación y metodologías para determinar el nivel de emisiones de GEl de individuos, organizaciones y unidades administrativas o territoriales, y la huella del carbono ( $\mathrm{HdC}$ ), es una de ellas (Padgett et al., 2008). La HdC, definida en forma muy general, representa la cantidad de gases efecto invernadero (GEI) emitidos a la atmósfera derivados de las actividades de producción o consumo de bienes y servicios y es medido en toneladas de $\mathrm{CO}_{2}$ por unidad de tiempo (Pandey et al., 2010). Como hay varios gases efecto invernadero, y no solo $\mathrm{CO}_{2}$, cuando se cuantifica la huella del carbono se considera el potencial de estos gases para expresar sus efectos como si fuera solo 
dióxido de carbono, concepto que se conoce como dióxido de carbono equivalente. Por ejemplo, la PCG, del metano $\left(\mathrm{CH}_{4}\right)$ es 25 veces más grande que la del $\mathrm{CO}_{2}$, y la $P C G$ del óxido nitroso $\left(\mathrm{N}_{2} \mathrm{O}\right)$ es 300 veces.

La HdC ha surgido en el dominio público en los últimos años, pero aún no existe una clara definición que sea comúnmente aceptada (Minx et al., 2008), aunque se encuentran antecedentes de marcos metodológicos utilizados para cálculo de la HdC desde los años 70 del siglo pasado (Daly, 1968; Leontief, 1971). Desde fines de los años 1980 se encuentran en la literatura aplicaciones de la HdC, aunque bajo nombres diferentes (Minx et al., 2010), y es calculada mediante diferentes metodologías. En la academia el tema ha experimentado también un notable desarrollo y de unas pocas publicaciones a fines del siglo pasado la literatura relacionada con la $\mathrm{HdC}$ ha experimentado un crecimiento exponencial en los últimos diez años (Espíndola y Valderrama, 2018)

Existen tres métodos principales en la literatura para el cálculo de la $\mathrm{HdC}$ en organizaciones, empresas, servicios, procesos y productos: i) Balance de Carbono (Bilan Carbone); ii) Especificaciones Públicamente Disponibles (PAS2050); y iii) Método Compuesto de las Cuentas Contables (MC3). Estos métodos son similares en la etapa de obtención de datos y son parte del análisis de ciclo de vida del producto. Una vez que se esquematiza el ciclo de vida del producto, esto es los procesos que ocurren desde que se extraen las materias primas hasta el lugar de su disposición final, cada método usa un enfoque diferente. La primera diferencia tiene lugar en la limitación del alcance de la empresa, es decir hasta dónde las emisiones de otros procesos influyen en el proceso en estudio. Una vez que se tiene el proceso bien delimitado, se extraen datos diferentes, para cada método. Una descripción más detallada es dada por los autores en su libro Huella del Carbono: Cambio climático, Gestión Sustentable y Eficiencia Energética (Espíndola y Valderrama, 2018).

Algunos autores sostienen que una huella, por el significado del concepto, debe abarcar todos los efectos que deja tras de sí una actividad. En el caso de una $\mathrm{HdC}$, debe incluir todas las emisiones de gases de efecto invernadero que se pueden asociar directa e indirectamente con una actividad, y por lo tanto, el análisis debe abarcar todo el ciclo de vida de un producto o servicio, desde las materias primas e insumos hasta el producto o servicio final. Metodológicamente, la HdC puede ser abordada dependiendo del enfoque o alcance específico. Para cada uno de estos enfoques existen diferentes protocolos o metodologías reconocidas internacionalmente. Los enfoques más conocidos son básicamente dos: enfoque corporativo y enfoque de producto.

En el enfoque corporativo se evalúa la $\mathrm{HdC}$ de una organización durante un periodo de tiempo establecido, usualmente un año calendario. La HdC corporativa agrupa las emisiones de GEl en tres alcances: (1) emisiones directas; (2) emisiones indirectas por consumo y distribución de energía; y (3) otras emisiones indirectas. La HdC corporativa se utiliza principalmente para la elaboración de informes corporativos que sirven de base para acreditar el desempeño de la empresa frente al cambio climático con todos los grupos de interés. En el enfoque de producto se evalúa la $\mathrm{HdC}$ de productos (bienes o servicios), a lo largo de toda la cadena de valor incluyendo, en algunos casos, el uso o consumo de éstos y el término de su vida útil. Este enfoque de productos ha tenido un gran impacto y desarrollo en Europa y Japón, manifestado por el creciente uso del etiquetado de productos en una tendencia creciente y que se extiende a otros países (Minx et al., 2010). La figura 1 muestra ejemplos sobre etiquetado de varios tipos de productos. De los ejemplos de la Tabla 1, el etiquetado de alimentos es el más expandido en el mundo, especialmente en Europa.

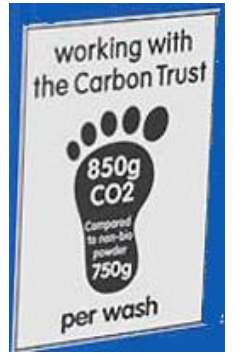

Detergentes

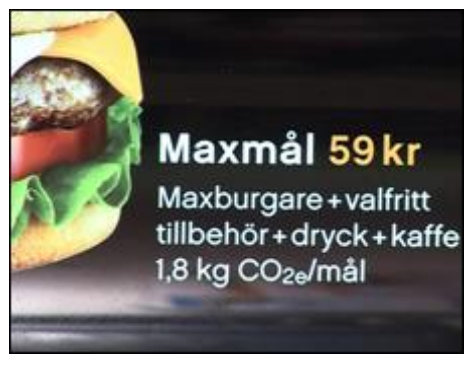

Alimentos

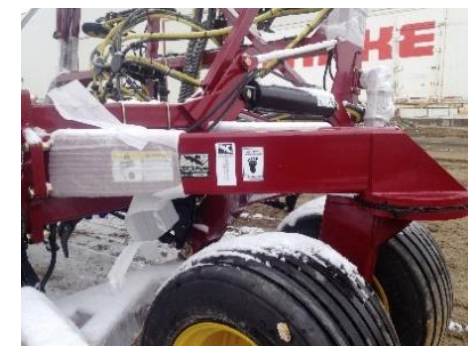

Maquinaria

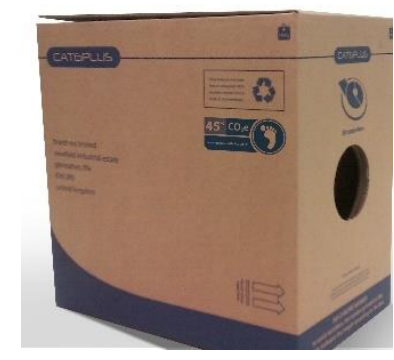

Electrónica

Fig. 1: Ejemplos sobre etiquetado de la $\mathrm{HdC}$ en productos

\section{LA HdC EN CHILE}

Chile ha empezado un proceso institucional de análisis de adaptación y respuesta a los desafíos planteados por las orientaciones europeas y estadounidenses, con la visión clara de lograr mantener y fortalecer su competitividad en el escenario internacional frente a vecinos latinoamericanos y a países de otras regiones. En particular, en mayo de 2009 se inició el estudio HdC en productos de exportación agropecuarios de Chile, que se desarrolló en el marco del Plan de Acción Nacional del Cambio Climático 2008-2010. El estudio ya incluía de forma explícita la $\mathrm{HdC}$ en las consideraciones de orden estratégico para enfrentar el cambio climático y cuantificar sus efectos. En paralelo, empresas grandes y medianas han empezado procesos 
voluntarios de cálculo de sus emisiones de GEI a nivel de sitios de producción. Este es el caso del sector forestal, vitivinícola, maderero y papelero, donde varias empresas implementan medidas de reducción y compensación. En el sector minero se está desarrollando un proyecto en el cual se busca reconocer potenciales emisores de GEI que pueden ser reducidos en sus faenas.

El sector más avanzado en Chile en la medición de la huella del carbono y uso de ella para optimizar sus procesos es el vitivinícola, situación que se explica, entre otros motivos, por la presión que ejercen algunos importadores europeos, su principal mercado. Las herramientas metodológicas utilizadas son, en la mayoría de los casos, replicas o adaptaciones del Protocolo GHG y del PAS 2050. En Chile, las empresas con mayores emisiones son las que generalmente informan su $\mathrm{HdC}$, en particular en el área minera, productiva, generadoras de energía y en algunos casos otras lo hacen por requerimiento del mercado.

Un informe conjunto de la Comisión Económica para América Latina y el Caribe (CEPAL) y la Organización para la Cooperación y el Desarrollo Económico (OCDE), detallan con bastante exactitud la situación chilena en materias ambientales, analizando algunos aspectos históricos y proyectando lo que debería ser Chile en el futuro cercano. El informe hace mención a varios aspectos: (i) La apertura al comercio internacional facilitó la penetración de las tecnologías ambientales de vanguardia; (ii) se redujo la huella ambiental de la industria; (iii) se expandió la generación eléctrica a partir de la energía solar y eólica; (iv) los gastos en investigación y desarrollo $(I+D)$ destinados al medio ambiente aumentaron hasta alcanzar en 2012 el 9\% del total de las erogaciones en $I+D ;(v)$ el número de solicitudes de patentes para tecnologías relacionadas con el medio ambiente aumentó en gran proporción; (vi) el sector chileno de los bienes y servicios ambientales creció a un ritmo más veloz que el resto de la economía. Y, aunque el informe no menciona en ninguna de sus partes el concepto de huella del carbono, usa el término huella ambiental, para la que una forma de medirla es la huella del carbono. Se sostiene también que "si se asegura una aplicación rigurosa de la normativa ambiental y se adoptan procedimientos de etiquetado ecológico y contrataciones públicas ecológicas en todas las etapas, se podría fomentar aún más la demanda de productos verdes" (CEPAL, 2013).

Hace unos pocos años, la sección Económica del diario El Mercurio de Chile (Emol, www.emol.cl) titulaba, "Ni siquiera el 1\% de las empresas en Chile mide sus huellas de carbono". El reportaje sostiene que mientras que, en los países del Reino Unido, probablemente los más avanzados en la aplicación y uso de la HdC, el $96 \%$ de las empresas mide e informa sobre la $\mathrm{HdC}$, mientras que en Chile hay solamente 132 empresas que miden su HdC. Esto representa aproximadamente el $1 \%$ del total de las compañías que registraron ventas en Chile durante 2013. En Chile no hay obligatoriedad para todas las empresas midan sus emisiones y las reporten periódicamente. Todo indica entonces que en Chile estamos atrasados en temas medioambientales y creemos que el futuro nos pasará la cuenta sino reaccionamos ahora mismo. Un ejecutivo sostiene que "Hay un desconocimiento (en nuestro país) de la problemática del cambio climático o la falta de recursos para hacerlo, tanto internos como externos (tiempo, información, financiamiento, entre otros). Esta última barrera tiende a reducirse cuando la estrategia climática de la empresa se vincula directamente con la gestión del negocio y especialmente con la estrategia comercial" (Emol, 2014). La situación no ha cambiado mucho en estos cinco o seis años, por lo que informaba Emol sigue vigente hoy en día.

\section{ENERGÍA EN EL SECTOR MINERO EN CHILE}

La matriz de energía primaria representa el aprovisionamiento energético del país, considerando la producción de recursos energéticos de Chile y los flujos de importación y exportación. Chile tiene una matriz energética bastante diversificada, la que durante el año 2017 alcanzó un total de 336.480 teracalorías (TCal). Este número se ha mantenido relativamente estable desde el año 2013 (con una pequeña baja del año 2015). Como se observa en la figura 2, el principal aporte proviene de los combustibles fósiles (petróleo crudo, gas natural y carbón) que suman un $68 \%$. El resto lo conforman la producción de biomasa (24\%), y en menor proporción hidroelectricidad, solar y eólica con un $8 \%$. El carbón, siendo una fuente muy contaminante de energía, aporta el $25 \%$ de toda la matriz. Sin embargo, petróleo y gas, que constituyen más de la mitad de toda la energía consumida, dependen de procesos de importación y, por lo tanto, se encuentran sujetos a factores externos de disponibilidad y precios en el mercado internacional lo que implica una condición de vulnerabilidad en la seguridad energética del país (ME-CNE, 2018; Espíndola y Valderrama, 2018).

La minería es uno de los principales consumidores de energía del país. De acuerdo a datos nacionales de consumo energético provistos por la Comisión Nacional de Energía, se estima que el sector minero es responsable directo del $14 \%$ del consumo energético del país, cifra que en general a 2017 significa un consumo total de energía de $169.923 \mathrm{TJ}$, consumo que mantiene una tendencia al alza en las últimas dos décadas. Desde el año 2006 a la fecha, el consumo de electricidad se ha mantenido relativamente estable entorno al $33 \%$ del total nacional mientras que consumo de diésel, el principal combustible minero, ha ido creciendo sustantivamente desde un 11.5\% en 2006 a un 23.5\% del consumo nacional para 2017 (Cochilco, 2018a). Del total de la energía consumida al año 2017 por la minería, la energía eléctrica comprende el 51.8\% y los combustibles (48.2\%), lo que en conjunto representan alrededor del $14 \%$ del consumo total del país (Cochilco, 2018a). 


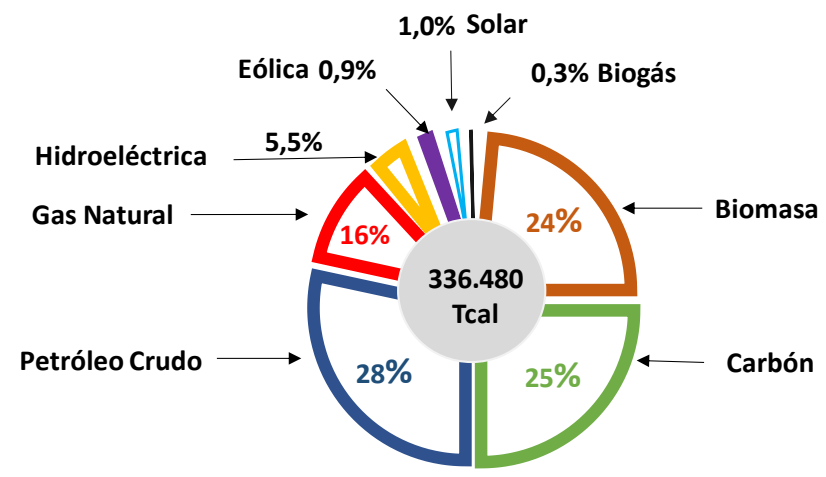

Fig. 2: Matriz de Energía Primaria de Chile 2017 (datos de ME-CNE, 2018)

En Chile se está poniendo en ejecución el nuevo Plan de Descarbonización que, entre sus principales puntos, establece el cierre de ocho centrales a carbón en los próximos cinco años y de todas al 2040, así como convertir a Chile en país carbono neutral al 2050. Se trata de un cambio notable en la matriz energética chilena, pero que es considerado insuficiente por organizaciones ambientalistas. La Fiscalía del Medio Ambiente (FIMA) propone que el cierre definitivo debería estar totalmente ejecutado en 2030 para frenar la emergencia climática mundial. Desde Greenpeace sostienen que el plan implica que estaremos retirando las centrales cuando hayan cumplido literalmente el doble de su vida útil. Desde la ONG WWF (World Wide Fund for Nature) dicen que se requiere mayor urgencia y ambición.

Desde el año 2013 la producción cuprífera ha caído un 4,7\%, mientras que el consumo energético ha crecido en un $9,7 \%$ en el mismo periodo, situación que proyecta un inevitable crecimiento de las emisiones de GEl y en consecuencia de la $\mathrm{HdC}$ de la industria minera cuprífera nacional. Si se analiza el consumo energético de electricidad y combustibles se puede determinar que en términos agregados los consumos son relativamente similares (88.066 TJ para electricidad y 81.857 TJ para combustibles). Sin embargo, a nivel de procesos, estos varían significativamente. En efecto, para el caso del consumo de combustibles, la mina a rajo abierto consume el $77 \%$ del total, seguido por fundiciones con un $9 \%$. Para el consumo eléctrico en cambio, el proceso de concentración es el más intensivo en consumo con un $57 \%$, seguido de la electro-obtención, con un $22 \%$.

\section{HdC Y MINERÍA EN CHILE}

Algunas empresas mineras en Chile han realizado ya por varios años la estimación y reporte público de la $\mathrm{HdC}$, de sus procesos y productos. La Comisión Chilena del Cobre (Cochilco) mantiene desde el año 1995 un inventario que permite la cuantificación y análisis de las emisiones de GEI directos de la minería del cobre a nivel nacional. La cuantificación se hace en forma simple considerando un alcance limitado: quema de los combustibles utilizados en las faenas, el uso de combustibles en el transporte de minerales, materiales y personal; en los procesos mineros y metalúrgicos, y en la administración y campamentos. Este informe en su cálculo incluye las emisiones de tres GEI (dióxido de carbono, metano y óxido nitroso, puesto que éstos son los GEI más relevantes para el caso de la minería del cobre, limitándose a las emisiones directas generadas por la combustión de combustibles fósiles en el proceso de producción de cobre (Cochilco, 2016). El inventario de emisiones de Cochilco incluye todos los procesos mineros, desde la extracción del mineral hasta la producción de los concentrados y cátodos de cobre, subdivididos en seis procesos unitarios genéricos: el área mina, el área de la planta concentradora, el área de lixiviación, el área de fundición, el área de refinería y finalmente el área de servicios.

Aun cuando el potencial de Chile en producción minera se ha mantenido, las condiciones que posibilitan el desarrollo de esta industria han cambiado. Los costos han aumentado, la productividad ha disminuido y la sostenibilidad ambiental y social se ha vuelto un imperativo para su desarrollo. Todos ellos constituyen desafíos que la industria debe enfrentar en el corto plazo si se desea asegurar la producción actual y materializar los proyectos futuros (FCH, 2016; Cochilco, 2015). En los últimos años el tema de la HdC en la industria minera ha seguido siendo de preocupación, aunque han aparecido otros temas relacionados y que al parecer son de mayor interés político, social e industrial. Todos los temas están relacionados y en todos ellos la $\mathrm{HdC}$ se presenta igual como una alternativa válida para cuantificar el grado de contaminación que aportan los distintos procesos y actividades de la minería.

Temas recurrentes y sobre los que se escribe y aporta información son: cambio climático en la industria minera, uso de tecnologías limpias, uso de agua de mar y energía en la minería, revolución energética, minería y desarrollo sostenible, comunidades y medio ambiente, reducción de la emisión de gases, recuperación de relaves, gestión integrada de recursos hídricos y eficiencia energética en minería. Esta preocupación de la minería queda evidenciada en los frecuentes escritos, reportajes y noticias sobre la HdC en la minería reportados por la Revista Minería Chilena (http://www.mch.cl) la que en los últimos ocho años ha publicado más de veinte artículos y reportajes sobre la HdC. Dada la alta demanda de energía de la industria minera, la 
aún baja participación de las energías renovables en la matriz energética chilena y el lento desarrollo de proyectos de energías alternativas, las empresas mineras en Chile seguirán amarradas a las fuentes de energía existentes (termoeléctricas y algo de generación hidráulica, a través del sistema interconectado central). Esto significa que la $\mathrm{HdC}$ o cualquier otra métrica para determinar el grado de contaminación atmosférica tendrá un lento avance de no modificarse estas condiciones de borde.

Algunos detractores sostienen que la $\mathrm{HdC}$ es un invento de los países desarrollados (léase hemisferio norte) que se impone al resto de las naciones pero que ellos mismos no son capaces de cumplir. Esto porque la posibilidad de generar energía eléctrica con métodos limpios hoy en día involucra costos notablemente más elevados que los métodos convencionales. Por lo tanto, lo que debe mejorar, sostienen, es la forma en que se usa la energía y no su fuente. Y entra en juego el concepto de eficiencia energética, un concepto que sin duda va de la mano con cambio climático y gestión sostenible. Independiente de todas estas visiones, lo cierto es que se seguirá produciendo gases nocivos, y como no tienen donde escapar se ubican en la estratosfera intensificando el efecto invernadero; a menos que no los dejemos escapar a la atmósfera y los contengamos en la tierra, o incluso los llevemos al espacio, más allá de nuestra atmósfera (Wong, 2007). La captura y almacenamiento de dióxido de carbono se presenta como una opción más en la lista de acciones para reducir o estabilizar el aumento de las concentraciones atmosféricas de GEl. Entre las opciones para la captura de $\mathrm{CO}_{2}$, está la carbonatación de algunos compuestos metálicos presentes en relaves mineros, para producir carbonatos altamente estables.

\section{LOS RELAVES Y SU REGULACIÓN EN CHILE}

Los relaves consisten en lodos de proceso (roca molida y efluentes) que se generan en una planta de procesamiento de minerales. Los procesos mecánicos y químicos que se utilizan para extraer el mineral, generalmente cobre, oro, plata y/o molibdeno producen una corriente de desechos conocida como relaves. Este proceso de extracción de productos nunca es $100 \%$ eficiente, ni es posible recuperar todos los reactivos y químicos utilizados en el proceso. Por lo tanto, metales, minerales, sustancias químicas, sustancias orgánicas y agua de procesos no recuperables y no rentables, se descargan, normalmente en forma de lodo, a un área de almacenamiento final, comúnmente conocida como depósito o almacenamiento de relaves. No es sorprendente que las características físicas y químicas de los relaves, sus métodos de manejo y el almacenamiento sean de gran preocupación social, lo que constituye para la gestión de la minería sostenible uno de los principales desafíos que debe enfrentar a nivel mundial esta industria, dado los potenciales impactos en la salud de las personas y los ecosistemas (Tailings.info, 2017).

En la mayoría de los países en que el sector minero es parte importante de la economía, las regulaciones ambientales también están avanzando, lo que impone requisitos más estrictos a la industria, en particular con respecto a las prácticas de almacenamiento de relaves. En última instancia, esto coloca una presión adicional sobre los operadores de una instalación de relaves que desempeñan las funciones diarias de descarga de relaves y gestión del agua. En Chile, el Reglamento para la Aprobación de Proyectos de Diseño, Construcción, Operación y Cierre de Depósitos de Relaves (BCN, 2007), señala que un depósito de relaves es toda obra estructurada para contener los relaves provenientes de una planta de concentración húmeda de especies minerales. En este sentido en la normativa nacional, se distinguen cinco tipos de depósitos de relaves clasificados según la tecnología de deposición de materiales. La Tabla 1 describe estos cinco tipos de relaves.

Tabla 1: Descripción de tipos de relaves, definidos en Chile (BCN, 2007)

\begin{tabular}{|l|l|l|}
\hline$N^{0}$ & Tipo & Descripción \\
\hline 1 & Embalse & $\begin{array}{l}\text { El embalse de relave, implica un muro de contención construido con material de empréstito (por } \\
\text { ejemplo, sacado de un cerro aledaño) y que se encuentra impermeabilizado en el coronamiento } \\
\text { (parte superior del muro) y en el talud (la pendiente interna del muro). También se llama embalses } \\
\text { de relaves a aquellos depósitos ubicados en alguna depresión de terreno en que no se requiere la } \\
\text { construcción de un muro de contención }\end{array}$ \\
\hline 2 & Filtrado & $\begin{array}{l}\text { El Relave filtrado, es el depósito de relaves donde los materiales son previamente sometidos a un } \\
\text { proceso de filtración para que su humedad sea inferior a 20\%. Esta filtración es también similar a la } \\
\text { utilizada en agua potable }\end{array}$ \\
\hline 3 & Pasta & $\begin{array}{l}\text { El relave en pasta, es el depósito de relaves que presenta una situación intermedia entre el relave } \\
\text { espesado y el filtrado, corresponde a una mezcla homogénea de relaves sólidos y agua (entre 10 y } \\
25 \% \text { de agua) que contiene partículas finas menores a 20 micrones, en una concentración en peso } \\
\text { superior al 15\% y su depósito se efectúa sin compactación, poseyendo consistencia coloidal }\end{array}$ \\
\hline 4 & Espesado & $\begin{array}{l}\text { El Relave espesado, es el depósito de relaves donde, antes de ser depositados, los relaves son } \\
\text { sometidos a un proceso de sedimentación mediante espesadores eliminándole una parte importante } \\
\text { del agua que contienen }\end{array}$ \\
\hline 5 & Tranque & $\begin{array}{l}\text { El tranque de relaves, implica la construcción de un muro de contención construido con la fracción } \\
\text { más gruesa del relave (arena). Existen además los depósitos de relaves al interior de túneles de } \\
\text { minas subterráneas y los depósitos construidos con un muro protector simple del mismo material del } \\
\text { relave. }\end{array}$ \\
\hline
\end{tabular}


En términos de tecnología, la eliminación de desechos mineros en Chile está caracterizado mayoritariamente por uso de tranques y embalses (tipo 1 en la Tabla 1), siendo un $97 \%$ de los depósitos de este tipo de tecnología. Así también recién se comienza a observar los primeros depósitos de relaves espesados al interior de minas subterráneas (tipo 4 en la Tabla 1) y el uso de muro de contención (tipo 5 en la Tabla 1), como tecnología de almacenamiento (Sernageomin, 2019). Cuando este análisis se efectúa según depósitos activos se puede observar que las regiones de Coquimbo y Atacama son las regiones con mayor cantidad de unidades en operación, mientras que en términos de tecnologías de deposición 88 de los 104 depósitos activos corresponden a tranques y embalses, en donde se encuentran yacimientos de sulfuros de cobre en explotación por flotación.

Desde 1992 a la fecha la ley mineral, es decir, la pureza con que se encuentra el cobre, ha caído visiblemente, en Chile, hasta un $46 \%$, transitando desde una ley de $1,6 \%$ hasta una de $0,87 \%$ en promedio. En el resto del mundo la caída de la ley ha alcanzado un $23 \%$ en promedio. Esto significa que en la década de 1990 había que sacar una tonelada de material para obtener 16 kilos de cobre fino, hoy, sólo se consiguen 8 kilos de mineral en promedio. Los continuos avances han mejorado la tecnología de extracción, se está explorando hasta por una ley de $0.3 \%$, a mayor profundidad y en condiciones de relieve cada vez más extremas. Así como las reservas probadas de cobre permiten inferir que la producción minera seguirá al alza durante al menos dos décadas más, lo lógico es proyectar que los relaves seguirán con un crecimiento exponencial (El Mostrador, 2015).

\section{DISTRIBUCIÓN DE RELAVES EN CHILE}

La situación 2019 de los relaves de la minería en Chile, da cuenta de la existencia de 742 depósitos con presencia en 10 de las 15 regiones, siendo Coquimbo (52.0\%), Atacama $(21,7 \%)$, Valparaíso $(10,5 \%)$ y Antofagasta (6.9\%) aquellas que concentran la mayor cantidad, con un $91,0 \%$ de los depósitos existentes en el país. De estas regiones Coquimbo presenta la mayor concentración del total de los depósitos del país, situación que se repite en cada uno de los tres estados de actividad de los relaves concentrando el $30,8 \%$ de los depósitos activos, el 53,3\% de los inactivos y el 61,3\% de los abandonados del país (Sernageomin, 2019).

La situación nacional muestra una mayor proporción de depósitos inactivos (463; 62.4\%), es decir han completado su vida útil y no han tenido plan de cierre de acuerdo a la ley, sin embargo, se conoce el titular de la instalación. Por otra parte, los depósitos en estado de abandono son 173 (23\%) encontrándose en operación solo 104 relaves que representan el $14.0 \%$ de los depósitos del país. La Tabla 2 describe los depósitos de relaves por tipo y región en Chile.

Tabla 2: Depósitos de relaves por tipo y región de emplazamiento (Sernageomin, 2019)

\begin{tabular}{|l|c|c|c|c|c|}
\hline \multicolumn{1}{|c|}{ Región } & Activos & Inactivos & Abandonados & Construcción & Total \\
\hline Tarapacá & 1 & 0 & 6 & & 7 \\
\hline Antofagasta & 13 & 22 & 16 & & 51 \\
\hline Atacama & 30 & 106 & 23 & 2 & 161 \\
\hline Coquimbo & 32 & 247 & 106 & & 385 \\
\hline Valparaíso & 14 & 53 & 11 & & 78 \\
\hline Metropolitana & 6 & 14 & 6 & & 26 \\
\hline O’Higgins & 3 & 15 & 1 & & 19 \\
\hline Maule & 4 & 2 & 0 & & 6 \\
\hline Aysén & 1 & 4 & 4 & & 9 \\
\hline Total & 104 & 463 & 173 & 2 & 742 \\
\hline
\end{tabular}

Si se desglosa por tamaño, de los 104 depósitos activos indicados en la Tabla 2, se puede determinar 32 de gran tamaño, entendiendo por esto aquellos cuyo volumen son superiores a 10 millones de metros cúbicos y 72 depósitos medianos y pequeños. La primera categoría de depósitos depositará alrededor de 15 mil millones de metros cúbicos de relave al final de su vida útil, que corresponde al 99,5\% del total nacional (Sernageomin, 2019). Según datos de Sernageomin las faenas de la gran minería han depositado a 2019 el $44,3 \%$ del total aprobado hasta el final de su vida útil. Por su parte, la minería de pequeña y mediana escala ha depositado el $60,3 \%$ de su volumen autorizado. Estos antecedentes permiten proyectar que ambas iniciativas se encuentran en la mitad de su ciclo de vida y por tanto en plena operación de sus faenas. La problemática de los relaves no solo puede ser descrita por el número de unidades de depósitos, sino también por el volumen de metros cúbicos de material el cual alcanza 16.047 millones de metros cúbicos como volumen total aprobado con depósitos que se distribuyen en 67 de las 346 comunas existentes en el país. 


\section{CAPTURA Y ALMACENAMIENTO DE $\mathrm{CO}_{2}$}

La captura y almacenamiento de dióxido de carbono (CAC) es una de las técnicas que podrían utilizarse para reducir las emisiones de $\mathrm{CO}_{2}$ a la atmósfera provocadas por las actividades humanas (Wang et al., 2017). Esta técnica podría aplicarse para aquellas emisiones que provengan de grandes centrales eléctricas 0 plantas industriales. El proceso consiste de tres etapas principales: (i) capturar el $\mathrm{CO}_{2}$ en su fuente, separándolo de los otros gases que se generan en los procesos industriales; (ii) transportar el $\mathrm{CO}_{2}$ capturado a un lugar de almacenamiento apropiado (normalmente de forma comprimida); y (iii) almacenar el $\mathrm{CO}_{2}$ al interior de la tierra por un largo periodo de tiempo, por ejemplo, en formaciones geológicas subterráneas, en las profundidades oceánicas o dentro de ciertos compuestos minerales. Algunas de las tecnologías que se requieren para este proceso están más avanzadas que otras y a mediados del año 2005 ya se habían desarrollado tres proyectos comerciales en los que el $\mathrm{CO}_{2}$ capturado se almacenaba en formaciones geológicas subterráneas, en el marco de proyectos de extracción o procesamiento de gas y petróleo. La Tabla 3 muestra una selección de proyectos recientes alrededor del mundo que usan la captura y almacenamiento de $\mathrm{CO}_{2}$ proveniente de sus procesos industriales de generación de energía.

Tabla 3: Proyectos sobre tecnología CAC en el mundo en los últimos cinco años.

\begin{tabular}{|l|l|l|l|l|}
\hline Proyecto & Ubicación & MW & Año & Detalles \\
\hline RWE & Alemania & 250 & 2014 & $\begin{array}{l}\text { Planta comercial Gasificación integrada en ciclo combinado con CAC en } \\
\text { precombustión }\end{array}$ \\
\hline Powerfuel & UK & 900 & 2015 & $\begin{array}{l}\text { Planta comercial Gasificación integrada en ciclo combinado con integración } \\
\text { completa de CAC }\end{array}$ \\
\hline RWE nPower & UK & 1000 & 2016 & $\begin{array}{l}\text { La nueva planta promete incluir CAC y ser una de las más modernas de } \\
\text { Europa }\end{array}$ \\
\hline Youngdong & Corea & 300 & 2018 & Reconversión de una unidad en oxicombustión \\
\hline GreenGen & China & 250 & 2018 & Planta comercial Gasificación integrada con integración completa de CAC \\
\hline Vattenfall & Alemania & 250 & 2020 & Planta de ciclo combinado usando CAC a gran escala para el año 2020 \\
\hline
\end{tabular}

Las tecnologías usadas por estas industrias representan un gran potencial para la reducción de las emisiones de $\mathrm{CO}_{2}$ en diferentes sectores, en especial en plantas en las que se produce directamente $\mathrm{CO}_{2}$ como consecuencia de los procesos, caso de las plantas de potencia que usan carbón, petróleo o gas natural. Existen diversas opciones tecnológicas para capturar el $\mathrm{CO}_{2}$. En una de ellas, el carbón se puede quemar como carbón pulverizado en la forma convencional y posteriormente se extrae el $\mathrm{CO}_{2}$ mediante tecnologías de absorción (es la denominada captura postcombustión). Asimismo, se puede capturar el $\mathrm{CO}_{2}$ en precombustión mediante la generación de hidrógeno después del proceso de gasificación, pero antes de la combustión. Una tercera posibilidad es obtenerlo ya concentrado, utilizando oxígeno puro en lugar de aire en la combustión, con lo que el flujo de gas tiene una concentración de $\mathrm{CO}_{2}$ superior al $95 \%$ (es el proceso denominado oxicombustión).

En la captura postcombustión se usa un disolvente químico (aminas y amoniaco), el cual se pone en contacto con la corriente de gases de salida provenientes de la combustión. Entonces dicho líquido absorbente reacciona con el $\mathrm{CO}_{2}$ y lo separa de la corriente. En otro reactor se produce la reacción inversa, es decir, se libera el $\mathrm{CO}_{2}$ ya concentrado, para que de esta forma el absorbente esté disponible para reaccionar de nuevo con el $\mathrm{CO}_{2}$. Los principales inconvenientes de este método se derivan de las condiciones de la corriente de gases de escape, ya que, al presentar un gran volumen, baja presión y presencia de impurezas y contaminantes, requiere de una elevada inversión económica en equipos de gran tamaño. Por otra parte, la baja concentración de $\mathrm{CO}_{2}$ en estos gases hace imprescindible el uso de sistemas de separación de alta eficiencia, por lo que el requerimiento energético es elevado.

La captura en precombustión consiste en convertir el combustible, mediante gasificación, en monóxido de carbono e hidrógeno, y posteriormente llevar a cabo la reacción gas-agua (reacción shift) para transformar el $\mathrm{CO}$ en $\mathrm{CO}_{2}$, el cual se puede separar mediante diversas tecnologías disponibles, previamente a la producción de electricidad. Este método de captura permite producir un combustible (hidrógeno) libre de carbono para su uso en calderas, turbinas, o pilas de combustible. Además, este método presenta varias ventajas frente a la postcombustión, como que el $\mathrm{CO}_{2}$ se separa de una corriente de gases de menor volumen, a una mayor presión y con una concentración en $\mathrm{CO}_{2}$ más elevada. La Tabla 4 clarifica algunos conceptos relacionados con la captura y almacenamiento de $\mathrm{CO}_{2}$, tales como: fuentes adecuadas para captura, tecnologías de captura, transporte de $\mathrm{CO}_{2}$, almacenamiento de $\mathrm{CO}_{2}$ bajo tierra o bajo el mar, y costo/eficiencia de las tecnologías 
Tabla 4: Algunos conceptos relacionados con la captura y almacenamiento de $\mathrm{CO}_{2}$.

\begin{tabular}{|c|c|}
\hline Concepto & Descripción \\
\hline $\begin{array}{l}\text { Fuentes de } \mathrm{CO}_{2} \\
\text { adecuadas para } \\
\text { captura }\end{array}$ & $\begin{array}{l}\text { Las fuentes de alta concentración de } \mathrm{CO}_{2} \text { son posibles candidatos para la implementación } \\
\text { temprana de Captura y Almacenamiento de } \mathrm{CO}_{2} \text { porque solo se requiere deshidratación y } \\
\text { compresión en la etapa de captura. }\end{array}$ \\
\hline $\begin{array}{l}\text { Tecnologías de } \\
\text { captura }\end{array}$ & $\begin{array}{l}\text { El propósito de la captura de } \mathrm{CO}_{2} \text { es producir un flujo concentrado de } \mathrm{CO}_{2} \text { a alta presión } \\
\text { que se pueda transportar fácilmente a un sitio de almacenamiento. Aunque, en principio, la } \\
\text { totalidad de la corriente de gas que contiene bajas concentraciones de } \mathrm{CO}_{2} \text { podría ser } \\
\text { transportada e inyectada bajo tierra. Los costos de energía y otros costos asociados } \\
\text { generalmente hacen que este enfoque sea impráctico. }\end{array}$ \\
\hline $\begin{array}{l}\text { Transporte de } \\
\mathrm{CO}_{2} \text { capturado }\end{array}$ & $\begin{array}{l}\text { Las tuberías de hoy operan como una tecnología de mercado madura y son el método más } \\
\text { común para el transporte de } \mathrm{CO}_{2} \text {. El } \mathrm{CO}_{2} \text { gaseoso generalmente se comprime a una presión } \\
\text { superior a } 8 \mathrm{MPa} \text { para evitar regímenes de flujo de dos fases y aumentar la densidad del } \\
\mathrm{CO}_{2} \text {. El } \mathrm{CO}_{2} \text { también se puede transportar como líquido en barcos, camiones cisterna o } \\
\text { trenes, en tanques aislados a una temperatura muy por debajo del ambiente y a presiones } \\
\text { mucho más bajas. }\end{array}$ \\
\hline $\begin{array}{l}\text { Almacenamiento } \\
\text { de } \mathrm{CO}_{2} \text { bajo } \\
\text { tierra }\end{array}$ & $\begin{array}{l}\text { Hay tres tipos de formaciones geológicas que han recibido una gran consideración por el } \\
\text { almacenamiento geológico de } \mathrm{CO}_{2} \text { : reservorios de petróleo y gas, formaciones salinas } \\
\text { profundas y yacimientos de carbón. En cada caso, el almacenamiento geológico de } \mathrm{CO}_{2} \text { se } \\
\text { realiza inyectándolo en forma densa en una formación de roca debajo de la superficie de la } \\
\text { tierra. }\end{array}$ \\
\hline $\begin{array}{l}\text { Almacenamiento } \\
\text { de } \mathrm{CO}_{2} \text { bajo el } \\
\text { mar }\end{array}$ & $\begin{array}{l}\text { Una opción potencial de almacenamiento de } \mathrm{CO}_{2} \text { es inyectar el } \mathrm{CO}_{2} \text { capturado directamente } \\
\text { en las profundidades del océano (a profundidades superiores a los } 1.000 \mathrm{~m} \text { ), donde la mayor } \\
\text { parte se aislaría de la atmósfera durante siglos. Esto se puede lograr transportando } \mathrm{CO}_{2} \text { a } \\
\text { través de tuberías o barcos a un lugar de almacenamiento en el océano, donde se inyecta } \\
\text { en la columna de agua del océano o en el fondo marino. El } \mathrm{CO}_{2} \text { disuelto y dispersado se } \\
\text { convertiría posteriormente en parte del ciclo global del carbono. Sin embargo, se debe } \\
\text { considerar los impactos producto de la acidificación de los océanos }\end{array}$ \\
\hline $\begin{array}{l}\text { Almacenamiento } \\
\text { en otros } \\
\text { materiales }\end{array}$ & $\begin{array}{l}\text { Entre otras varias alternativas, la carbonatación mineral, que consiste en convertir } \mathrm{CO}_{2} \text { en } \\
\text { carbonatos inorgánicos sólidos utilizando reacciones químicas y el uso industrial de } \mathrm{CO}_{2} \text {, } \\
\text { ya sea directamente o como materia prima para la producción de diversos productos } \\
\text { químicos que contienen carbono, son vías que se estudian en varios países. }\end{array}$ \\
\hline $\begin{array}{l}\text { Costo eficiencia } \\
\text { de las } \\
\text { tecnologías }\end{array}$ & $\begin{array}{l}\text { La rigurosidad de los requisitos futuros para el control de las emisiones de gases de efecto } \\
\text { invernadero y los costos esperados de los sistemas de CAC determinarán, en gran medida, } \\
\text { el futuro despliegue de tecnologías de CAC en relación con otras opciones de mitigación de } \\
\text { gases de efecto invernadero. Los costos deben incluir los costos externos, como los daños } \\
\text { ambientales y los costos sociales más amplios que pueden estar asociados al uso de CAC. }\end{array}$ \\
\hline
\end{tabular}

La oxicombustión consiste en realizar la combustión con oxígeno puro o enriquecido en lugar de aire, de modo que los gases de escape contienen fundamentalmente $\mathrm{CO}_{2}$ y agua, libres de nitrógeno, con lo cual se facilita la separación del $\mathrm{CO}_{2}$. Se trata de una técnica probada industrialmente con combustibles convencionales. Los inconvenientes de este método estriban en el alto costo de producción de oxígeno y la necesidad de recircular grandes cantidades de gases de escape para mantener la temperatura de combustión. Se puede decir que en realidad es un tipo de postcombustión ya que la separación del $\mathrm{CO}_{2}$ se produce después de la producción de electricidad. Por tanto, la diferencia entre las diferentes opciones tecnológicas mencionadas radica en el momento en el cual se produce la captura. En dichas tres opciones se ha de producir, finalmente, la compresión y deshidratación (secado) del $\mathrm{CO}_{2}$ para obtener una corriente concentrada de $\mathrm{CO}_{2}$ que sea posteriormente susceptible de ser almacenada geológicamente.

Las tecnologías CAC no evitan la generación de gases de efecto invernadero, pero sí prometen evitar que se emitan a la atmósfera y, por tanto, que disminuya su impacto en el clima durante largos periodos de tiempo. El desarrollo de almacenamientos geológicos para el $\mathrm{CO}_{2}$ capturado, sumado a los sumideros naturales puede proporcionar un tiempo adicional hasta que las medidas de reducción y prevención de emisiones consideradas prioritarias sean completamente efectivas. No obstante, también los sumideros geológicos son limitados y además se requiere un consumo adicional de recursos fósiles para la implementación y uso de las tecnologías de captura que, incluso, van en la dirección de reducir la expectativa de vida del carbón. Estas razones hacen que la captura y el almacenamiento no sean en sí una opción sostenible, pero sí representan una solución transitoria a la mitigación del cambio climático. Es más, representan sólo una tecnología "puente" hasta que las fuentes energéticas renovables estén lo suficientemente desarrolladas en cantidad y precio. 


\section{SECUESTRACIÓN DE $\mathrm{CO}_{2}$ MEDIANTE CARBONATACIÓN}

La secuestración de dióxido de carbono mediante carbonatación mineral es una tecnología que incluye la reacción de $\mathrm{CO}_{2}$ con óxidos o silicatos de magnesio, calcio o hierro para producir carbonatos altamente estables. El proceso puede ser resumido mediante la reacción general de la ec. (1):

$$
(\mathrm{Ca}, \mathrm{Mg}, \mathrm{Fe}) \mathrm{SiO}_{3}(\mathrm{~s})+\mathrm{CO}_{2}(\mathrm{~g}) \rightarrow(\mathrm{Ca}, \mathrm{Mg}, \mathrm{Fe}) \mathrm{CO}_{3}(\mathrm{~s})+\mathrm{SiO}_{2}(\mathrm{~s})
$$

La estabilidad de los productos de la reacción de carbonatación se explica por el átomo de carbono que está a su más bajo nivel de energía en el carbonato, lo que provee una vida de almacenamiento de más de 100 mil años (Rackley, 2010). Esta tecnología es atractiva también por la abundancia en la naturaleza de este tipo de silicatos existiendo capacidad para secuestrar todo el $\mathrm{CO}_{2}$ emitido por los procesos de combustión de combustibles fósiles (Lackner et al., 1995; IPCC, 2005). Importante de mencionar es también el hecho de que la reacción de carbonatación es exotérmica presentando entonces oportunidad para integración energética. Un esquema genérico de un proceso de carbonatación se muestra en la figura 3.

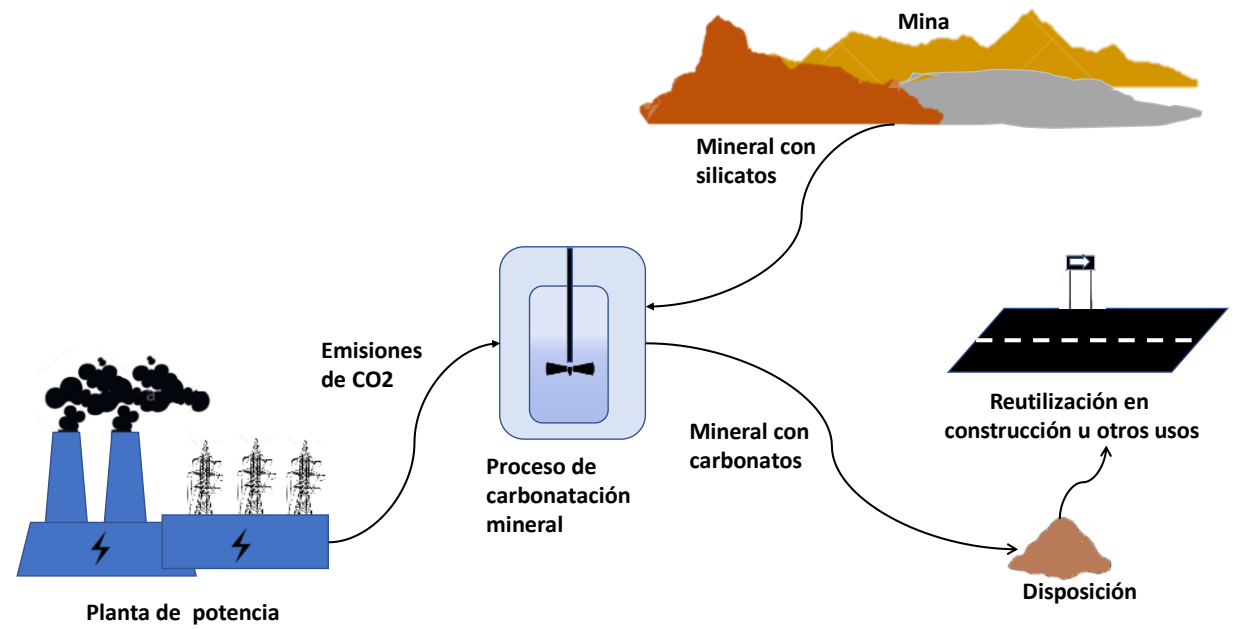

Fig. 3: Esquema general del proceso de carbonatación mineral (adaptado de Global CCS Institute, 2011)

La carbonatación mineral no es más que un proceso de desgaste natural que ocurre a escalas geológicas, y por lo tanto el proceso es extremadamente lento. Se han presentado varios estudios para acelerar este proceso, incluyendo carbonatación directa del mineral con $\mathrm{CO}_{2}$ hasta complejos procesos multietapas (Rackley, 2010; Olajire, 2013). El interés principal de los estudios en este campo ha estado orientados a acelerar la velocidad de reacción de carbonatación de manera de justificar su implementación industrial. Los procesos de carbonatación mineral han sido clasificados en los de tipo ex-situ (fuera del lugar natural de existencia del mineral o del relave) y los de tipo in-situ (directo a los depósitos minerales).

La ruta más simple de carbonatación en términos del diseño y operación del proceso es la ruta directa gas/sólido. Sin embargo, en este proceso la reacción es muy lenta, incluso a elevadas temperaturas y presiones (Huijgen y Comans, 2003). Por esta razón este camino ha sido abandonado, aunque unos pocos investigadores alrededor del mundo trabajan en ello (Fagerlund et al., 2010; Zevenhoven et al., 2011; Slotte et al., 2013). Más interés ha tenido la carbonatación acuosa directa que al parecer tiene más ventajas que la vía gas/sólida (O'Connor et al., 2000; Bonfils et al., 2012).

La carbonatación acuosa consiste en dos etapas, que tienen conflictos al momento de optimizar el proceso: extracción de los metales alcalino térreos de los silicatos minerales mediante disolución, seguido de una carbonatación de los cationes disueltos a través de la formación de carbonatos, por precipitación. Un pH bajo y una alta temperatura son óptimas para la etapa de disolución mientras que la etapa de precipitación es favorecida por un pH alto y una temperatura más moderada (Gerdemann et al., 2007). Este proceso esta entonces limitado en términos de optimización considerando la complejidad del proceso de carbonatación (Haug, 2010). Varios autores han propuesto modificaciones a este método como se muestra en la Tabla 5.

Relaves ricos en magnesio de la industria del platino en Sudáfrica han sido identificados como materia prima potencialmente viable y atractiva para el secuestro de $\mathrm{CO}_{2}$ a través de la carbonatación mineral. Ncongwane (2016) describe cuatro procesos para la carbonatación de silicato de magnesio: i) proceso acuoso directo; ii) proceso de sales de amonio; iii) proceso Lackner con ácido clorhídrico; y iv) proceso de la universidad Ảbo Akademi de Finlandia (AAU). Los cuatro procesos se resumen en la Tabla 6. 
Tabla 5: Diversas propuestas presentadas en la literatura para el proceso de carbonatación acuosa directa

\begin{tabular}{|l|l|}
\hline Autores & Propuestas \\
\hline Park et al. 2003 & $\begin{array}{l}\text { El proceso propuesto involucra disolver minerales de silicato a pH bajo usando } \\
\text { soluciones ácidas y posteriormente carbonatar el lixiviado en condiciones alcalinas. } \\
\text { Esto proporciona la oportunidad de optimizar los pasos de reacción de disolución y } \\
\text { carbonatación individualmente. }\end{array}$ \\
\hline $\begin{array}{l}\text { Park y Fan., 2004; Alexander } \\
\text { et al., 2007; Gerdemann et al., } \\
\text { 2007; Meyer et al., 2014 }\end{array}$ & $\begin{array}{l}\text { La etapa de disolución se considera el paso de limitación de velocidad en la } \\
\text { carbonación mineral acuosa y gran parte de la investigación y el desarrollo de } \\
\text { sistemas de carbonatos minerales diseñados se ha centrado en los métodos para } \\
\text { mejorar la cinética de la etapa de disolución. }\end{array}$ \\
\hline $\begin{array}{l}\text { Gerdemann et al., 2007; Teir } \\
\text { et al., 2006; Wang y Maroto- } \\
\text { Valer, 2011 }\end{array}$ & $\begin{array}{l}\text { Para acelerar la cinética de disolución, se sugiere condiciones agresivas de lixiviación } \\
\text { (pH bajo, T y P elevadas, ácidos fuertes) y/o pretratamiento como la activación } \\
\text { mecánica y térmica. Sin embargo, estas condiciones son demandantes de energía y } \\
\text { pueden aumentar significativamente la HdC. }\end{array}$ \\
\hline
\end{tabular}

Tabla 6: Reacciones químicas en tres procesos de carbonatación de silicato de magnesio (adaptada de Ncongwane (2016)

\begin{tabular}{|c|c|c|c|}
\hline Proceso & Reacción Química & $T\left({ }^{\circ} \mathrm{C}\right)$ & $P($ atm $)$ \\
\hline \multicolumn{4}{|l|}{ 1) Proceso acuoso directa } \\
\hline Reacción $\mathrm{H}_{2} \mathrm{O} / \mathrm{CO}_{2}$ & $\mathrm{H}_{2} \mathrm{O}+\mathrm{CO}_{2} \rightarrow \mathrm{H}_{2} \mathrm{CO}_{3}$ & 185 & 150 \\
\hline Carbonatación mineral & $\mathrm{MgSiO}_{3}+\mathrm{H}_{2} \mathrm{CO}_{3} \rightarrow \mathrm{MgCO}_{3}+\mathrm{SiO}_{2}+\mathrm{H}_{2} \mathrm{O}$ & 185 & 150 \\
\hline \multicolumn{4}{|c|}{ 2) Proceso de sales de amonio } \\
\hline Disolución mineral & $\mathrm{MgSiO}_{3}+2 \mathrm{NH}_{4} \mathrm{HSO}_{4} \rightarrow \mathrm{MgSO}_{4}+\mathrm{SiO}_{2}+\left(\mathrm{NH}_{4}\right)_{2} \mathrm{SO}_{4}+\mathrm{H}_{2} \mathrm{O}$ & 90 & 1 \\
\hline Ajuste de $\mathrm{pH}$ & $\mathrm{NH}_{4} \mathrm{HSO}_{4}+\mathrm{NH}_{4} \mathrm{OH} \rightarrow\left(\mathrm{NH}_{4}\right)_{2} \mathrm{SO}_{4}+\mathrm{H}_{2} \mathrm{O}$ & 25 & 1 \\
\hline Carbonatación Mineral & $\mathrm{MgSO}_{4}+\mathrm{NH}_{4} \mathrm{HCO}_{3}+\mathrm{H}_{2} \mathrm{O} \rightarrow \mathrm{MgCO}_{3} \cdot 6 \mathrm{H}_{2} \mathrm{O}+\left(\mathrm{NH}_{4}\right)_{2} \mathrm{SO}_{4}+\mathrm{CO}_{2}$ & 80 & 1 \\
\hline Captura de $\mathrm{CO}_{2}$ & $\mathrm{CO}_{2}+\mathrm{NH}_{3}+\mathrm{H}_{2} \mathrm{O} \rightarrow \mathrm{NH}_{4} \mathrm{HCO}_{3}$ & 10 & 1 \\
\hline Regeneración & $\left(\mathrm{NH}_{4}\right)_{2} \mathrm{SO}_{4} \rightarrow \mathrm{NH}_{3}+\mathrm{NH}_{4} \mathrm{HSO}_{4}$ & 300 & 1 \\
\hline \multicolumn{4}{|c|}{ 3) Proceso Lackner con ácido clorhídrico } \\
\hline Disolución mineral & $\mathrm{MgSiO}_{3}+2 \mathrm{HCl}+5 \mathrm{H}_{2} \mathrm{O} \rightarrow \mathrm{MgCl}_{2} \cdot 6 \mathrm{H}_{2} \mathrm{O}+\mathrm{SiO}_{2}$ & 70 & 1 \\
\hline Conversión & $\mathrm{MgCl}_{2} \cdot 6 \mathrm{H}_{2} \mathrm{O} \rightarrow \mathrm{MgO}+2 \mathrm{HCl}+5 \mathrm{H}_{2} \mathrm{O}$ & 150 & 1 \\
\hline Repartición & $2 \mathrm{MgO}+2 \mathrm{HCl} \rightarrow \mathrm{Mg}(\mathrm{OH})_{2}+\mathrm{MgCl}_{2}$ & 25 & 1 \\
\hline Carbonatación Mineral & $\mathrm{Mg}(\mathrm{OH})_{2}+\mathrm{CO}_{2} \rightarrow \mathrm{MgCO}_{3}+\mathrm{H}_{2} \mathrm{O}$ & 407 & 1 \\
\hline \multicolumn{4}{|c|}{ 4) Proceso de la universidad Åbo Akademi (AAU). } \\
\hline Extracción de Mg & $\mathrm{MgSiO}_{3}+\left(\mathrm{NH}_{4}\right)_{2} \mathrm{SO}_{4} \rightarrow \mathrm{MgSO}_{4}+\mathrm{SiO}_{2}+2 \mathrm{NH}_{3}+\mathrm{H}_{2} \mathrm{O}$ & 400 & 1 \\
\hline Precipitación & $\mathrm{MgSO}_{4}+2 \mathrm{NH}_{3}+2 \mathrm{H}_{2} \mathrm{O} \rightarrow \mathrm{Mg}(\mathrm{OH})_{2}+\left(\mathrm{NH}_{4}\right)_{2} \mathrm{SO}_{4}$ & 40 & 1 \\
\hline Carbonatación Mineral & $\mathrm{Mg}(\mathrm{OH})_{2}+\mathrm{CO}_{2} \rightarrow \mathrm{MgCO}_{3}+\mathrm{H}_{2} \mathrm{O}$ & 450 & 20 \\
\hline
\end{tabular}

Entre los procesos de carbonatación acuosa, el proceso más intensivo en energía es el proceso Lackner con ácido clorhídrico, mientras que el proceso acuoso directo es el menos intensivo. La Tabla 7 resume los gastos de agua y energía. Entre los procesos acuosos indirectos, la relación entre la cantidad de agua y los requisitos de energía es evidente, y los requisitos de energía del proceso aumentan a medida que aumenta el consumo de agua. El impacto del cambio de fase también es evidente en los requisitos de energía mucho más grandes del proceso de $\mathrm{HCl}$ de Lackner y las sales de amonio en comparación con el proceso de la Universidad Abo Akademi, que no implica cambio de fase. Sin embargo, el proceso acuoso directo, aunque utiliza más agua (18 mil kg / h), utiliza menos energía que el proceso de las sales de amonio (13 mil kg / h). Estas observaciones sugieren que para que los procesos de carbonatación mineral acuosa reduzcan algunos de sus requerimientos de energía, se debe evitar operaciones unitarias que consuman mucha energía y que impliquen cambios de fase como la evaporación. 
Tabla 7: Gastos de agua y energía para los diferentes procesos de carbonatación mineral de silicatos de magnesio (Ncongwane (2016))

\begin{tabular}{|l|c|c|}
\hline Proceso de carbonatación acuosa & Agua (kg/hr) & Energía (MJ/hr) \\
\hline Acuoso directa & 17984 & 6073 \\
\hline Lackner con ácido clorhídrico & 25071 & 229962 \\
\hline De sales de amonio & 12839 & 105349 \\
\hline De la universidad Åbo Akademi (AAU). & 11843 & 14760 \\
\hline
\end{tabular}

\section{LÍQUIDOS IÓNICOS PARA LA CAPTURA Y TRASPORTE DE $\mathrm{CO}_{2}$}

Una alternativa que está siendo intensamente estudiada para la captura de $\mathrm{CO}_{2}$ es la absorción mediante líquidos iónicos (LIs). Los LIs se definen comúnmente como materiales formados solo por iones (anión y catión) y que tienen una temperatura de fusión bajo $100^{\circ} \mathrm{C}$. Hasta la fecha, se ha sintetizado una amplia gama de Lls mediante diferentes combinaciones de aniones y cationes y se estima que el número teórico de IL que podrían ser sintetizados es de varios miles de millones $\left(\approx 10^{18}\right)$. Los LIs poseen algunas características únicas y atractivas, tales como alta estabilidad química y térmica, baja presión de vapor, gran ventana electroquímica, naturaleza ajustable, y excelentes propiedades solventes para una gama de compuestos polares y no polares. Habiendo tantas posibles combinaciones entre aniones y cationes, es altamente factible encontrar un LI que sea óptimo para la absorción y trasporte de $\mathrm{CO}_{2}$ (Gurkan et. al., 2010). La idea está aún lejos de convertirse en aplicación industrial, más por razones económicas que por dificultades técnicas.

Ramdin et al. (2012) hacen una extensa revisión de la literatura sobre el tema de la captura de $\mathrm{CO}_{2}$ en líquidos iónicos, hasta el año 2012. Los autores presentan un extenso análisis de varios aspectos del proceso y muestran algunos resultados. Importante entre ellos es que muestran la alta capacidad de absorción de $\mathrm{CO}_{2}$ por varios líquidos iónicos a presiones no muy altas. La figura 4 muestra la solubilidad de $\mathrm{CO}_{2}$ a $298 \mathrm{~K}$ en varios líquidos iónicos, observándose que hay varios líquidos iónicos que pueden disolver una gran cantidad de $\mathrm{CO}_{2}$ a presiones moderadas (bajo $5 \mathrm{MPa}$ ). En otras unidades, lo mostrado en la figura 4 equivale a decir que se puede absorber unos 60 a 120 kilos de $\mathrm{CO}_{2}$ por metro cúbico de IL a presiones bajo $5 \mathrm{MPa}$, para los LIs mostrados en la figura. La base de datos sobre LIs del National Institute of Standards and Technology (NIST, 2019) presenta un listado de más de 300 artículos que contienen 7388 datos de solubilidad de $\mathrm{CO}_{2}$ en líquidos iónicos.

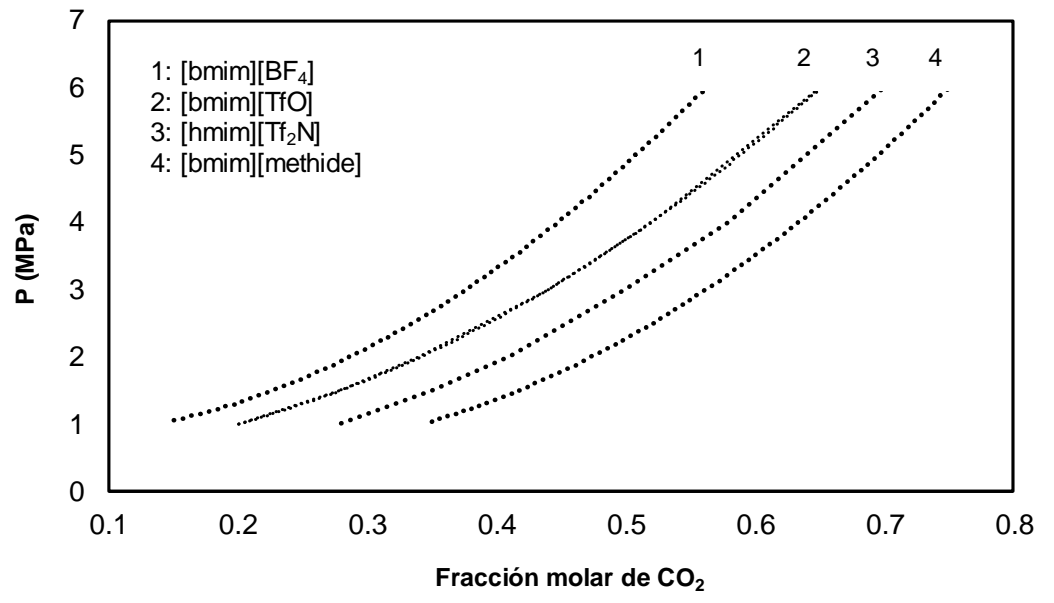

Fig. 4: Solubilidad de $\mathrm{CO}_{2}$ a $298 \mathrm{~K}$ en varios líquidos iónicos. Datos de Ramdin et al. (2012)

La especial característica de alta absorción de $\mathrm{CO}_{2}$ por parte de los Lls junto a sus propiedades de baja volatilidad, los hace candidatos adecuados para idear un proceso completo que contemple captura, transporte y separación de $\mathrm{CO}_{2}$ que use solo líquidos iónicos. En esta propuesta, el $\mathrm{CO}_{2}$ es absorbido por el líquido iónico en el absorbedor, en una o más etapas, dependiendo de las selectividades del LI por el $\mathrm{CO}_{2}$ y los otros gases de chimenea de las plantas de potencia. Una vez absorbido el $\mathrm{LI}$ rico en $\mathrm{CO}_{2}$ puede seguir dos caminos: (i) regenerar el líquido iónico (por ejemplo, calentando el líquido iónico con el $\mathrm{CO}_{2}$ absorbido, liberando el $\mathrm{CO}_{2}$, para luego trasportar el $\mathrm{CO}_{2}$ puro al lugar de secuestración; o (ii) transportar el líquido iónico al lugar de secuestración, liberando allí el $\mathrm{CO}_{2}$ para luego secuestrarlo. La figura 5 presenta una propuesta para la captura de $\mathrm{CO}_{2}$ de gases de chimenea. En la fig. 5, el $\mathrm{CO}_{2}$ para secuestración que aparece al tope del regenerador puede ir directo a secuestración si el regenerador está en el lugar de la generación de relaves, o puede ir a transporte (tuberías, camiones, tren, barco) si el proceso de regeneración se hizo junto a la planta de fuerza o en otro lugar alejado de donde se procesa el mineral y se genera el relave. Un estudio técnico económico deberá resolver el camino más factible. 


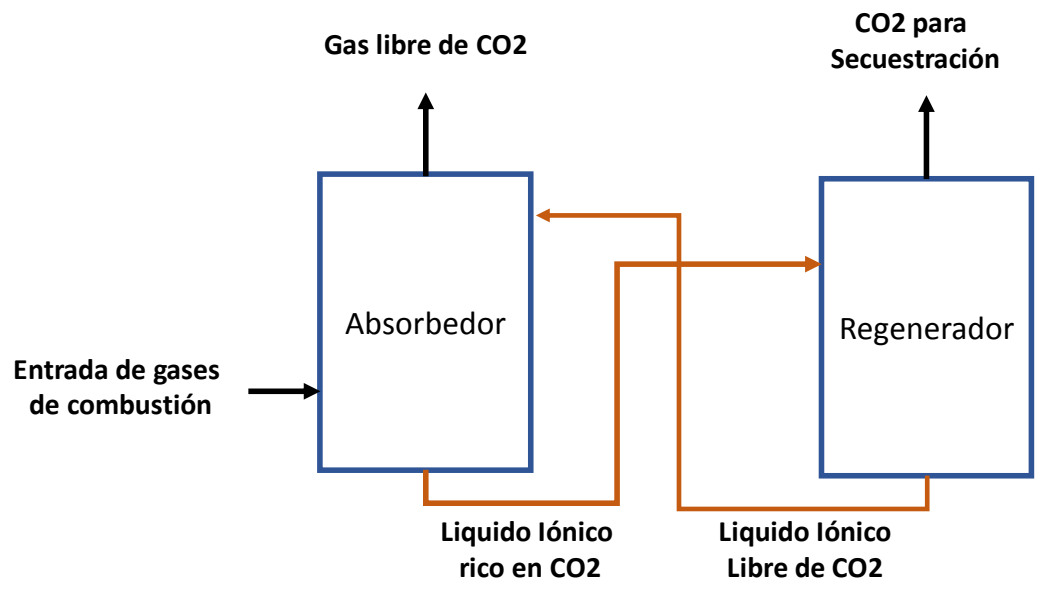

Fig. 5: Esquema propuesto para la captura de $\mathrm{CO}_{2}$ en un líquido iónico y su separación para ser enviado secuestrado (adaptado de Torrealba-Calleja et al., 2013)

En la actualidad, la mayor parte del desarrollo relacionado con los LIs para la captura de $\mathrm{CO}_{2}$ se realiza a escala de laboratorio, mientras que otras aplicaciones ya están en uso a escala industrial. Para llegar a la aplicación e implementación industrial de un proceso como el propuesto en la figura 5 es necesario lograr un mayor conocimiento de las propiedades físicas y químicas de los líquidos iónicos, en especial la posibilidad de predecir las propiedades, considerando la cantidad extremadamente grande de posibilidades de cambiar aniones y cationes, que genera millones de líquidos iónicos. Por lo tanto, se requiere de técnicas de correlación y predicción y por cierto más datos experimentales para seleccionar el líquido iónico adecuado para diseñar un proceso de captura y trasporte que sea ecológica- y económicamente viable.

\section{DISCUSIÓN FINAL}

Según datos registrados en el Anuario de Estadísticas del Cobre y otros minerales, las emisiones directas totales de gases efecto invernadero de la minería nacional del cobre para el año 2017, alcanzaron a 5.98 millones de toneladas métricas de $\mathrm{CO}_{2}$ equivalente (Cochilco 2018b). Estas emisiones representan un crecimiento del $47 \%$ respecto de los niveles registrados en el año 2008 (4.08 millones de toneladas métricas de $\mathrm{CO}_{2}$ equivalente). El deterioro de la calidad del recurso minero, específicamente la disminución de las leyes de cobre, en los actuales yacimientos, ha configurado un escenario bajo el cual las compañías mineras deben hacer grandes esfuerzos para mantener su nivel de producción. A esto se agrega el problema de las emisiones de GEI.

Durante los últimos 15 años, la minería en Chile ha aumentado sus emisiones de gases invernadero debido al mayor consumo de electricidad y de combustibles producto de las razones explicadas anteriormente. La aplicación de políticas de eficiencia energética y la incorporación de fuentes de energías renovables no convencionales a la matriz energética constituyen actualmente las principales medidas utilizadas por las compañías mineras para disminuir su huella de carbono (Collahuasi, 2015). No obstante, éstas no son suficientes para reducir de manera significativa las emisiones directas e indirectas. La captura y secuestración de $\mathrm{CO}_{2}$ puede ayudar en este esfuerzo. Aun cuando el potencial de Chile en producción minera se ha mantenido intacto, las condiciones que posibilitan el desarrollo de esta industria han cambiado. Los costos han aumentado, la productividad ha disminuido y la sostenibilidad ambiental y social se ha vuelto un imperativo para su desarrollo (FCH, 2016; Cochilco, 2015).

\section{CONCLUSIONES}

De acuerdo al estudio realizado, la discusión de los diversos temas, y las propuestas realizadas en este trabajo, se puede plantear las siguientes conclusiones principales: (i) La generación eléctrica a partir del uso de combustibles fósiles ha ido en aumento en Chile y recién se han planteado un plan gubernamental de descarbonización, para convertir a Chile en un país carbono-neutral para el año 2050; (ii) En Chile, las empresas con mayores emisiones informan su $\mathrm{HdC}$, pero solamente un grupo reducido de éstas tiene obligatoriedad de declarar; (iii) El desarrollo de almacenamientos geológicos para el $\mathrm{CO}_{2}$ capturado, sumado a los sumideros naturales puede proporcionar un tiempo adicional hasta que las medidas de reducción y prevención de emisiones sean efectivas; (iv) La captura y almacenamiento de dióxido de carbono (CAC) es una de las técnicas que debieran utilizarse para reducir las emisiones de $\mathrm{CO}_{2}$ provocadas por las actividades de generación de energía; (v) La secuestración de $\mathrm{CO}_{2}$ mediante carbonatación mineral acuosa es una tecnología que incluye la reacción de $\mathrm{CO}_{2}$ con óxidos o silicatos de metales como $\mathrm{Mg}$, $\mathrm{Fe}$ y $\mathrm{Ca}$, y que puede ser aplicada a la minería chilena; vi) El proceso de carbonatación podría integrarse a alguno de los procesos del tratamiento de minerales para reducir costos; y vii) Los líquidos iónicos representan una atractiva forma de captura y transporte de $\mathrm{CO}_{2}$ para su secuestración en relaves mineros. 


\section{AGRADECIMIENTOS}

Los autores agradecen a la Comisión Nacional de Investigación Científica y Tecnológica CONICYT por el apoyo a través del proyecto Anillo ACM170005 del Programa de Investigación Asociativa titulado Tailings \& Sea Water: from End-of-Pipe Towards Cleaner Production. RCC y CAE agradecen también a la Dirección de Investigación y Desarrollo de la Universidad de La Serena por permanente apoyo.

\section{REFERENCIAS}

Alexander, G., N. Mercedes Maroto-Valer y P. Gafarova-Aksoy, Evaluation of reaction variables in the dissolution of serpentine for mineral carbonation, Fuel, 86(1), 273-281 (2007)

BCN (Biblioteca del Congreso Nacional de Chile), Decreto 248: Aprueba reglamento para la aprobación de proyectos de diseño, construcción, y cierre de los de relaves (2007)

BCN (Biblioteca del Congreso Nacional de Chile), La contaminación del aire en Asia Pacífico y las medidas para reducir la polución (2017)

BME, Boletín Mercado Eléctrico, Sector Generación, Generadoras de Chile AG, http://generadoras.cl (2018)

Bolin, B., B.R. Döös, J. Jäger y R.A. Warrick, The greenhouse effect, climatic change and ecosystems, International Council of Scientific Unions, Paris (Francia), Scientific Committee on Problems of the Environment, 541 (1986)

Bonfils, B., C. Julcour-Lebigue y otros cuatro autores, Comprehensive analysis of direct aqueous mineral carbonation using dissolution enhancing organic additives, International Journal of Greenhouse Gas Control, 9, 334-346 (2012)

CEPAL, Metodologías de cálculo de la Huella de Carbono y sus potenciales implicaciones para América Latina, Documento de Trabajo (2013)

COCHILCO (Comisión Chilena del Cobre), Factores Claves para el desarrollo de la Minería en Chile (2015)

COCHILCO (Comisión Chilena del Cobre), Informe de actualización de emisiones de GHG en la minería del cobre (2016)

COCHILCO (Comisión Chilena del Cobre), Informe de actualización del consumo energético de la minería del cobre al año 2017 (2018a)

COCHILCO (Comisión Chilena del Cobre), Proyección de la producción de cobre en Chile 2018 - 2029 (2018b)

Collahuasi, Compañía Minera doña Inés de Collahuasi, Reporte de Desarrollo Sustentable (2015)

Daly, H.E., On Economics as a Life Science, Journal of Political Economy, 76, 392-406 (1968)

ECOticias, https://www.ecoticias.com/naturaleza/181922/arrecifes-coral-bajo-yugo-CO2. 16 de marzo (2018)

EL Mostrador, Sernageomín cifra en casi 1 millón y medio las toneladas de relaves producidas en Chile (2015)

Emol, Diario El Mercurio, Santiago de Chile, 5 de abril de 2014, documento escrito por Marisel Muñoz Brand (2014)

Espíndola, C. y J. Valderrama, Huella del Carbono. Cambio climático, gestión sustentable y eficiencia energética, Editorial Universidad de La Serena, Chile (2018)

Fagerlund, J., E. Nduagu, I. Romao y R. Zevenhoven, A stepwise process for carbon dioxide sequestration using magnesium silicates, Frontiers of Chemical Engineering in China, 4(2), 133-141 (2010)

FCH (Fundación Chile), Desde el cobre a la Innovación Roadmap 2015-2035, Programa Nac. de Minería Alta Ley (2016)

Gerdemann, S.J., W.K. O'Connor y otros tres autores, Ex situ aqueous mineral carbonation, Environmental Science \& Technology, 41(7), 2587-2593 (2007)

Global CCS Institute, https://www.globalccsinstitute.com/ (2011)

Gurkan, B., B.F. Goodrich y otros 11 autores, Molecular Design of High Capacity, Low Viscosity, Chemically Tunable lonic Liquids for CO2 Capture. DOI: 10.1021/jz101533k, J. Phys. Chem. Lett. 1, 3494-3499 (2010)

Hall-Spencer, J. M., Harvey, B.P. Ocean acidification impacts on coastal ecosystem services due to habitat degradation, Emerging Topics in Life Sciences, 3 (2) 197-206 (2019)

Haug, T.A., Dissolution and carbonation of mechanically activated olivine -Investigating $\mathrm{CO} 2$ sequestration possibilities, (2010)

Huijgen, W.J.J. y R.N.J. Comans, Carbon dioxide sequestration by mineral carbonation: Literature Review, Energy research Centre of the Netherlands ECN (2003)

IPCC, 2005 - B. Metz, O. Davidson, H. de Coninck, M. Loos y Leo Meyer (Eds.) Cambridge University Press, UK. Pp. 431. Available from Cambridge University Press, Cambridge CB2 2RU ENGLAND (2005)

IPCC, Intergovernmental Panel on Climate Change, United Nations Environment Programme (UNEP) and the World Meteorological Organization (WMO), http://www.ipcc.ch (2005)

Lackner, K.S., Wendt y otros tres autores, Carbon dioxide, Carbon dioxide disposal in carbonate minerals, Energy, 20 (11) 1153-1170 (1995) 
Leontief, W. y D. Ford, Air Pollution and the Economic Structure: Empirical Results of Input-Output Calculations. Paper presentado en la 5 ${ }^{\text {a }}$ Int. Conference on Input-Output Techniques North Holland Pub. Co Geneva, Suiza (1971)

LT, Entrevista sección LT-Pulso del diario La Tercera (Chile), por Juan Manuel Villagrán, Enero (2019)

ME-CNE (Ministerio de Energía Chile-Comisión Nacional de Energía), Anuario Estadístico de Energía 2018 (2019)

Meyer, N., J.U. Vögeli y otros cuatro autores, Mineral carbonation of PGM mine tailings for $\mathrm{CO}_{2}$ storage in South Africa: A case study, 10.1016/j.mineng.2013.10.014, Minerals Engineering, 59, 45-51 (2014)

Minx, J.C., G.P. Peters, T. Wiedmann e Y.J. Barrett, GHG Emissions in the Global Supply Chain of Food Products. The 2008 International Input-Output Meeting on Managing the Environment (IIOMME), Seville, Spain, July 9-11 (2008)

Minx, J.C., T. Wiedman y otros 14 autores, Input-Output analysis and carbon footprinting: an overview of applications, https://doi.org/10.1080/09535310903541298, Economic Systems Research, 21(3), 187-216 (2010)

Montecinos, S. y D. Carvajal, Energía Renovables: Escenario Actual y perspectivas Futuras, Editorial Universidad de La Serena, Chile (2018)

Ncongwane, M.S., Assessment of the Potential Carbon Footprint of Engineered Processes for the Mineral Carbonation of PGM Tailings, MSc Thesis Chem. Eng., Univ. de Ciudad del Cabo, Sud Africa, http://hdl.handle.net/11427/20951 (2016)

NIST National Institute of Standards and Technology, https://www.nist.gov/ (2019)

O'Connor, W.K., Dahlin y otros tres autores, Actas de la 25a International Technical Conference on Coal Utilization and Fuel Systems, Clearwater, FL (US), 2000. Edited by B.A. Sakkestad, Coal Technology Association, Rockville, Md. (2000)

Olajire, A., A Review of Mineral Carbonation Technology in Sequestration of $\mathrm{CO}_{2}$, Doi:10.1016/j.petrol.2013.03.013, Journal of Petroleum Science and Engineering, 109, 364-392 (2013)

OMM, World Meteorological Organization, https://public.wmo.int/en (2018)

Padgett, P., A. Stenemann, J. Clarke y M.A. Vanderbergh. A Comparison of Carbon Calculators, Environmental Impact Assessment Review, 28, 106-115 (2008)

Pandey, D., M. Agrawal y J.S. Pandey. Carbon footprint: current methods of estimation. Environmental Monitoring and Assessment, 178(1-4), 135-160 (2010)

Park, A.A. y L. Fan, $\mathrm{CO}_{2}$ mineral sequestration: physically activated dissolution of serpentine and $\mathrm{pH}$ swing process, Chemical Engineering Science, 59(22), 5241-5247 (2004)

Park, A.A., R. Jadhav y L. Fan, $\mathrm{CO}_{2}$ mineral sequestration: chemically enhanced aqueous carbonation of serpentine, The Canadian Journal of Chemical Engineering, 81(3-4), 885-890 (2003)

Rackley, S., Carbon capture and storage, Butterworth-Heinemann Pub., Holland, ISBN: 9781856176361 (2010)

Ramdin, M, T.W. de Loos, T.J.H. Vlugt, State-of-the-Art of $\mathrm{CO}_{2}$ Capture with lonic Liquids, https://doi.org/10.1021/ie3003705, Ind. Eng. Chem. Res., 51(24) 8149-8177(2012)

Sernageomin (Servicio Nacional de Geología y Minería de Chile), Datos Públicos Depósito de Relaves (2019)

Slotte, M., I. Romao y R. Zevenhoven, Integration of a pilot-scale serpentinite carbonation process with an industrial lime kiln, DOI: https://doi.org/10.1016/j.energy.2013.07.009. Energy, 62 (1) 142-149 (2013)

Tailing.info, http://www.tailings.info/basics/tailings.htm. What Are Tailings? - Their nature and production (2017)

Teir, S., S. Eloneva, C-J. Fogelholm y R. Zevenhoven, Stability of calcium carbonate and magnesium carbonate in rainwater and nitric acid solutions, DOI: 10.1016/j.enconman.2006.03.021, Energy, Conversion and Management, 47(18), 3059-3068 (2006)

Torrealba-Calleja, E., J. Skinner y D. Gutiérrez-Tauste, $\mathrm{CO}_{2}$ Capture in lonic Liquids: A Review of Solubilities and Experimental Methods, http://dx.doi.org/10.1155/2013/473584, Journal of Chemistry, Article ID 473584, 16 pages (2013)

Wang, X. y M.M. Maroto-Valer, Dissolution of serpentine using recyclable ammonium salts for $\mathrm{CO}_{2}$ mineral carbonation, https://doi.org/10.1016/j.fuel.2010.10.040, Fuel, 90(3), 1229-1237 (2011)

Wang, F., D.B. Dreisinger, M. Jarvis y T. Hitchins (2017): The Technology of CO2 Sequestration by Mineral Carbonation: Current status and Future Prospects, DOI: 10.1080/00084433.2017.1375221, Canadian Metallurgical Quarterly, 57, 4658 (2018)

Wiedmann, T. y J. Minx, A Definition of Carbon Footprint In: C. C. Pertsova, Ecological Economics Research Trends, №1, 1-11, Nova Science Publishers, Hauppauge NY, USA (2008)

Wong, A.Y., A stairway to heaven? The Economist, 2 de junio (2007)

WRI, Resources Institute, The Greenhouse Gas Protocol, A Corporate Accounting and Reporting Standard, https://ghgprotocol.org/sites/default/files/standards/ghg-protocol-revised.pdf, Marzo (2004)

Zevenhoven, R., J. Fagerlund y J.D. Songok, $\mathrm{CO}_{2}$ mineral sequestration: developments toward large-scale application, Greenhouse Gases, Science and Technology, 1(1), 48-57 (2011) 